\title{
CENTRO COLABORADOR EM ALIMENTAÇÃO E NUTRIÇÃO ESCOLAR (CECANE/UFT) NO ESTADO DO TOCANTINS
}

\author{
Lisandra Lustoza Ferro \\ Universidade Federal do Tocantins \\ lisandraferro@gmail.com \\ Claudia Jaqueline Fialho \\ Universidade Federal do Tocantins \\ claudiajf@uft.edu.br \\ Renata Andrade de Medeiros Moreira \\ Universidade Federal no Tocantins \\ renatamoreira@mail.uft.edu.br
}

Daiara Rakeli Simão Boyarski

Universidade Federal do Tocantins daiararakeli@gmail.com

Dayane Justos dos Santos Universidade Federal do Tocantins dayanejustoo@gmail.com

Izabela Ribeiro Rodrigues Universidade Federal do Tocantins izarodrigu@gmail.com

Mariana de Menezes Universidade Federal Tocantins mariana.menezes97@gmail.com

\section{Resumo}

Os Centros Colaboradores em Alimentação e Nutrição Escolar (CECANE) são parcerias entre o Fundo Nacional de Desenvolvimento da Educação (FNDE) e as Instituições Federais de Ensino Superior, que tencionam realizar apoio técnico e operacional à execução do Programa Nacional de Alimentação Escolar (PNAE), de forma a garantir a oferta de alimentação adequada e saudável aos discentes de escolas públicas e filantrópicas. Dentre as atividades implementadas pelo CECANE da Universidade Federal do Tocantins (UFT) destaca-se as assessorias e monitoramentos à 36 municípios nos anos de 2016 à 2017, contribuindo para a capacitação de recursos humanos responsáveis pelo PNAE e levantamento de dados acerca da execução. Conclui-se que há a necessidade da ininterrupção das ações do CECANE/UFT, para atender continuamente o maior quantitativo de municípios e atores sociais do PNAE, de modo a promover a eficaz execução do PNAE.

Palavras-chave: Alimentação Escolar. Programa Nacional de Alimentação Escolar. Formação de Atores Sociais do PNAE. Segurança Alimentar e Nutricional. Agricultura Familiar.

\section{COLLABORATING CENTER ON FOOD AND SCHOOL NUTRITION (CECANE/UFT) IN STATE OF TOCANTINS}

Abstract

The Collaborating Center on Food and School Nutrition (CECANE) are partnerships between the National Fund for the Development of Education (FNDE) and Federal Institutions for Higher Education, which intend to provide technical and operational support to the implementation of the National School Feeding Program (PNAE), in order to guarantee the supply of adequate and healthy food to the students of public and philanthropic schools. Among the activities implemented by CECANE of the Federal University of Tocantins (UFT), it is worth noting the advising and monitoring of 36 municipalities in the years 2016 to 2017 , contributing to the training of human resources responsible for PNAE and data collection on execution. It is concluded that there is a need for the continuation of CECANE / UFT actions, in order to continuously serve the largest number of municipalities and social actors of the PNAE, in order to promote the effective execution of the PNAE.

Keywords: School Feeding. National School Feeding Program. Formation of Social Actors of the PNAE. Food and Nutrition Security. Family Farming.

\section{CENTRO COLABORADORES EM ALIMENTACIÓN Y NUTRICIÓN ESCOLAR (CECANE/UFT) EN EL ESTADO DEL TOCANTINS}

\section{Resumen}

Los Centros Colaboradores en Alimentación y Nutrición Escolar (CECANE) son asociaciones entre el Fondo Nacional de Desarrollo de la Educación (FNDE) y las Instituciones Federales de Enseñanza Superior, que tienen intención de realizar apoyo técnico y operacional a la ejecución del Programa Nacional de Alimentación Escolar (PNAE), a fin de garantizar la oferta de alimentación adecuada y saludable a los alumnos de escuelas públicas y filantrópicas. Entre las actividades implementadas por el CECANE de la Universidad Federal de Tocantins (UFT) se destacan las asesorías y monitoreos a 36 municipios en los años 2016 a 2017, contribuyendo a la capacitación de recursos humanos responsables del PNAE y levantamiento de datos sobre la ejecución. Se concluye que hay la necesidad de la ininterrumpida de las acciones del CECANE /UFT, para atender continuamente el mayor cuantitativo de municipios y actores sociales del PNAE, para promover la eficaz ejecución del PNAE.

Palabras claves: Alimentación Escolar. Programa Nacional de Alimentación Escolar. Formación de Actores Sociales del PNAE. Seguridad Alimentaria y Nutricional. Agricultura Familiar. 


\section{INTRODUÇÃO}

O Programa Nacional de Alimentação Escolar (PNAE) garante a oferta de alimentação aos discentes de escolas públicas e instituições filantrópicas no Brasil (BRASIL, 2015), sendo responsável pelo atendimento a 41,5 milhões de estudantes no ano de 2015 (BRASIL, 2018), de forma a "contribuir para o crescimento do aluno nas áreas social, cognitiva, emocional e principalmente, nutricional" (REZER, 2015), sendo regulamentado pela Lei 11.947/2009 (BRASIL, 2009) e Resolução 26/2013 (BRASIL, 2013), que dispõem sobre o atendimento da alimentação escolar.

Salienta-se que o PNAE é a política de segurança alimentar e nutricional mais antiga do país, implementada a fim de minimizar os principais problemas de saúde pública da época como a desnutrição e doenças provenientes de deficiências nutricionais. Durante as décadas de implementação o programa alterou-se, até possuir as características atuais, como gestão descentralizada e atendimento universal (HAMERSCHMIDT, 2014).

A gestão descentralizada promove a atuação das Entidades Executoras e do Fundo Nacional do Desenvolvimento da Educação (FNDE), este último é a autarquia vinculada ao Ministério da Educação, responsável pela transferência de recursos financeiros federais às Entidades Executoras, para garantir a implementação de projetos e programas (BRASIL, 2018).

Realça-se que a descentralização do programa possibilitou a maior responsabilidade para as Entidades Executoras de gerenciamento do PNAE (ASSAO, 2012), o planejamento de cardápios adequados aos hábitos culturais de cada região e a maior participação da sociedade, com a formação de Conselhos de Alimentação Escolar (CAE), que fiscalizam a aplicação de recursos pelas entidades executoras e escolas (SPINELLI, 2002).

Outras mudanças que garantiram o avanço do PNAE foi a obrigatoriedade do nutricionista como responsável técnico pelo programa, pela Resolução no 32/2006 (BRASIL, 2006), tendo como funções o planejamento de cardápios, o acompanhamento do processo de licitação, o recebimento de produtos, a realização de atividades de educação alimentar e nutricional, dentre outras atribuições, que o torna um dos atores responsáveis por assegurar a oferta de alimentação adequada e saudável nas escolas (BRASIL, 2010).

Ressalta-se que a atuação do FNDE também é primordial para a melhor execução do PNAE, cujas responsabilidades abrangem, além da função mencionada anteriormente, a coordenação do programa, a partir do estabelecimento das normas gerais de planejamento, execução, controle, monitoramento e avaliação (BRASIL, 2015).

Para possibilitar a efetivação das funções de assessoria e monitoramento, estabeleceu-se parceria entre o FNDE e as Instituições Federais de Ensino Superior, iniciando-se a criação de 
Centros Colaboradores em Alimentação e Nutrição Escolar (CECANE) (BRASIL, 2006). No ano de 2018 totaliza-se 16 CECANE (FNDE, 2018) que proporcionam apoio técnico e operacional aos estados e municípios, a fim de garantir a correta execução do PNAE, de acordo com a demanda apresentada por cada região e/ou estado.

Destaca-se que em 2015, houve a criação do CECANE da Universidade Federal do Tocantins (UFT), que iniciou suas atividades em campo em 2016, com assessoria e monitoramento em 36 municípios até o final de 2017, possibilitando a capacitação de diferentes atores do programa como conselheiros, nutricionistas, secretários de educação, coordenadores da alimentação e agricultores familiares (BRASIL, 2006).

Diante do exposto, este trabalho objetiva apresentar as ações do CECANE/UFT nos anos de 2016 à 2017, apresentando os resultados das ações e as demandas encontradas nos municípios.

\section{METODOLOGIA}

A formação da equipe do CECANE/UFT ocorre anualmente, a partir de processo de seleção realizado por docentes responsáveis pelo projeto, de forma a eleger agentes nutricionistas e estagiários. Antes de iniciar as atividades, ocorreu a capacitação da equipe, com estudos dos questionários fornecidos pelo FNDE, legislação vigente e formação do plano de atividades a serem desenvolvidas nos municípios.

Assim, em 2016 e 2017 o FNDE apresentou a demanda para equipe do CECANE/UFT de Assessoria e Monitoramento aos municípios, totalizando 12 cidades em 2016 e 24 em 2017. Os critérios de seleção empregados pelo FNDE no primeiro ano foram a demanda dos órgãos de controle, presença de denúncias, ter mais que 30\% dos recursos na conta, não ter prestado contas de forma apropriada e inexistência da compra da agricultura familiar; todos caracterizados como critérios negativos para a gestão.

Enquanto que no ano de 2017 houveram, também, municípios selecionados por critérios positivos, como compra da agricultura com pelo menos 30\% dos recursos, registro de pelo menos 3 ações de educação alimentar e nutricional, prestação de contas aprovadas e uso de 50\% ou mais de recursos próprios para alimentação escolar comparado ao valor repassado pelo FNDE.

A partir da seleção dos municípios, realizavam-se coletas de dados em bancos de dados acerca da quantidade de escolas, discentes e docentes; valores repassados; se possuía nutricionista; 
CAE ativo ou inativo; e compra da agricultura familiar nos últimos anos. No Gráfico 1 expõe-se critérios de seleções dos municípios, diferenciando-se pelo ano.

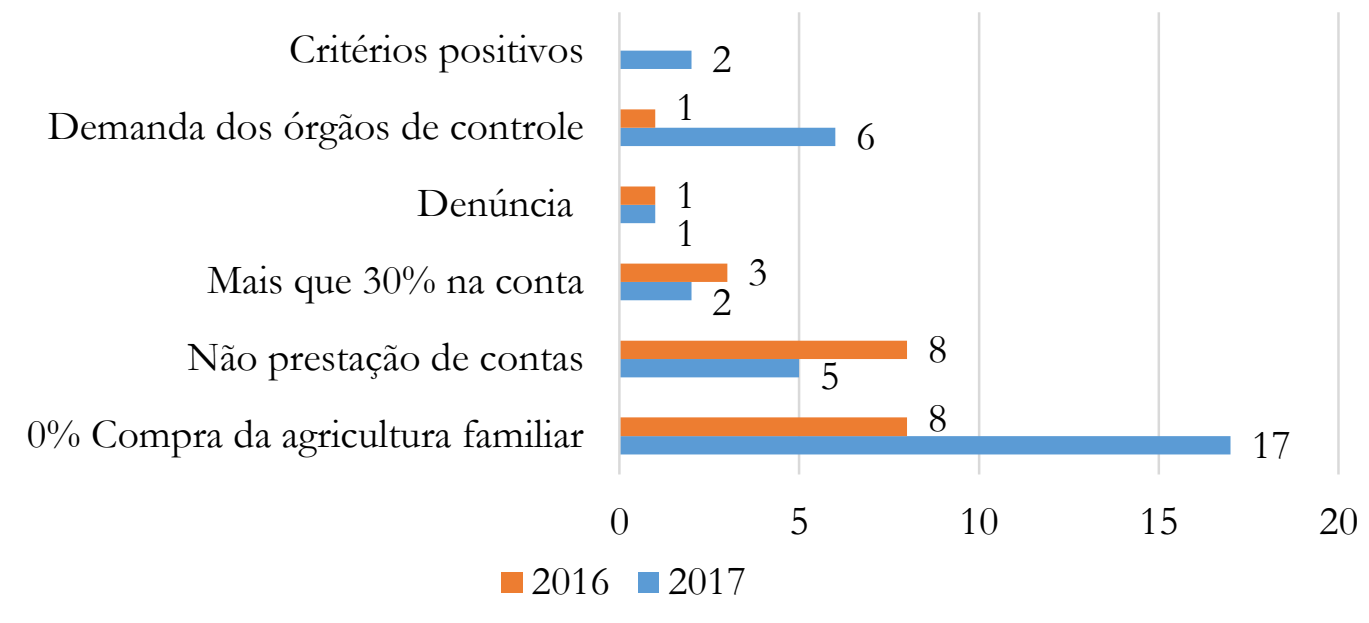

Gráfico 1. Critérios de seleção dos municípios para assessoria e monitoramento nos anos de 2016 e 2017 do Centro Colaborador de Alimentação Escolar da Universidade Federal do Tocantins.

Fonte: Dados obtidos pelo CECANE/UFT. Tocantins. 2016 e 2017.

As assessorias e monitoramentos aos municípios duraram em média 4 dias, alterando em alguns municípios devido a logística de transporte e a demanda das cidades. No primeiro dia as atividades concentravam-se em reuniões com nutricionistas, secretários, CAE, coordenadores da alimentação escolar e representantes financeiros, com apresentação do CECANE, esclarecimento do motivo da assessoria e monitoramento; em contrapartida o município apresentava sua realidade de execução do Programa, de forma a serem sanadas as primeiras dúvidas que eram expostas.

No segundo dia, realizava-se reunião apenas com os gestores (secretários e representantes financeiros), para realizar a fiscalização das documentações exigidas de antemão. Esclarecia-se sobre as formas de licitações e orientava-se como realizá-las, além de aplicação de questionário destinado às Entidades Executoras.

No terceiro dia buscava-se realizar as visitas às escolas, propiciando a coleta de dados acerca das Unidades de Alimentação e Nutrição Escolares e orientação aos manipuladores de alimentos, quando possível. Cumpria-se também reunião com as nutricionistas, aplicava-se questionário e orientava-se sobre a necessidade de realização de atividades de educação alimentar e nutricional e cumprimento de outras atribuições, prevista em legislações (BRASIL, 2009; 2010).

Posteriormente foram realizados encontros com agricultores familiares ou representantes para orientação sobre a emissão de selos para os produtos exigidos pela Vigilância Sanitária, 
como o Selo de Inspeção Municipal e Selo de Inspeção Federal (BRASIL, 1950) e declaração de aptidão para fornecimentos de produtos, como exigido pelo PNAE (BRASIL, 2015), além de ser explicado sobre o objetivo do programa, funcionamento e importância da participação dos mesmos.

Nas reuniões com o CAE buscou-se identificar as atividades realizadas, com aplicação de questionário e sanava-se as dúvidas quanto a formação do conselho, funções, confecção do plano anual, o que observar nas visitas às escolas e como elaborar o regime interno e livro de atas, de acordo com a legislação vigente (BRASIL, 2015).

Após as reuniões separadas com cada grupo de atores, reunia-se todos e apresentavam-se o plano de ação, com as deficiências encontradas para serem solucionadas com prazos correspondentes. O quarto dia de assessoria e monitoramento destinava-se a efetuar a formação de atores envolvidos com o PNAE das cidades vizinhas, em que a cidade monitorada responsabilizava-se por disponibilizar infraestrutura para a formação.

As formações iniciavam-se com dinâmicas, e seguia-se com exposição dialogada, com interação dos participantes, de maneira a propiciar o melhor aprendizado a partir de trocas de experiências. Os temas abordados nas formações incluíam o que é o CECANE e seus objetivos; a trajetória histórica do PNAE, objetivos, valores repassados e suas legislações atualizadas; bem como funções inerentes ao FNDE, CAE, gestores e nutricionistas no PNAE.

Além dos assuntos introdutórios, a formação apresentava a importância da articulação dos gestores e nutricionista com os agricultores familiares e CAE; como efetuar a inserção dos nutricionistas no Sistema Integrado de Monitoramento Execução e Controle; como proceder para a formação e renovação do conselho.

Por fim, tratava-se da agricultura familiar, como o processo de aquisição de gêneros alimentícios e a importância de incentivar o consumo dos produtos regionais. Para finalização, abria-se momento para discussão e aplicava-se modelo de avaliação da oficina com escala hedônica facial.

\section{RESULTADOS E ANÁLISES}

Nos dois municípios selecionados por critérios positivos em 2017 (Gráfico 1), Krahô e Javaé, verificou-se falhas. Em Krahô apesar de haver a compra de produtores familiares acima de $30 \%$, na chamada pública observou-se processos aceitos de farinha de puba e polpa de fruta sem comprovação de certificação sanitária, o que contradiz as legislações vigentes (BRASIL, 2015). 
Enquanto que em Javaé identificou-se a compra superior à 30\% dos recursos federais da agricultura familiar, com articulação entre órgão de apoio técnico aos agricultores, Ruraltins, Secretarias de Agricultura e Educação. Porém, nos dois municípios, devido desconhecimento das incumbências pelo CAE e acerca da prestação de contas, situações já descritas em literatura (SANTOS, 2007), havia prestações aprovadas com irregularidades, como a aquisição de gêneros não alimentícios com o recurso do PNAE, em desacordo à legislação (BRASIL, 2015).

Destaca-se que em Krahô, além das incorreções na prestação de contas aprovadas pelo CAE identificou-se que o conselho era pouco ativo, com ausência de registro em atas das ações efetuadas, além de ser observado conflito de interesse pelo presidente do conselho, uma vez que o mesmo era presidente, representante dos pais de alunos e diretor em escola municipal, o que pode interferir nos resultados das avaliações a serem realizadas pelo conselho.

Destaca-se que pela legislação, a formação do CAE deve conter um ente indicado pelo Poder Executivo do ente federado, representantes dos docentes e trabalhadores da educação, representantes de pais e alunos e representantes indicados por entidades civis, com a responsabilidade de fiscalizar, deliberar e assessorar o programa, de forma a propiciar a execução eficiente do PNAE (BRASIL, 2015).

Tanto em Javaé, quanto em Krahô ao avaliar as compras realizadas com o recurso destinado à alimentação escolar verificou-se que os gêneros não alimentícios eram adquiridos com este, como materiais de limpeza, e não havia detalhamento dos valores de recursos próprios usados na aquisição de alimentos pelas escolas, o que é incompatível com a Legislação 11.947/2009 (BRASIL, 2015).

Salienta-se que os valores repassados pelo FNDE, de acordo com a quantidade de estudantes, modalidade de ensino e quantidade de dias letivos, devem ser complementados com a contrapartida das Entidades Executoras, destinada à aquisição de gêneros alimentícios, de forma a garantir o fornecimento da alimentação durante todo o período letivo e o alcance das necessidades nutricionais previstas na legislação (BRASIL, 2015), além da compra de gêneros não alimentícios (OLIVEIRA, 2018).

Ressalta-se que em Krahô não houve colaboração do setor financeiro; o nutricionista não estava registrado no Sistema Integrado de Monitoramento Execução e Controle e cumpria carga horária de 20 horas mensais, considerada insuficiente para a realização de suas atribuições (CFN, 2010). Sobressai-se que o cumprimento de carga horária inferior ao preconizado é uma inadequação comum à vários municípios, sendo a maioria 20 horas semanais, além de que nem todos os municípios assessorados possuíam responsável técnico contratado, detectando-se a ausência em 50\% dos municípios no ano de 2016 e em 20\% dos municípios em 2017. 
Inconformidades em relação à carga horária cumprida e a designada pela Resolução $n^{\circ} 465 / 2010$ (CFN, 2010) para nutricionistas no PNAE foram observadas em outras literaturas (VOOS, 2009; SOUZA, 2017), que apontam a necessidade de ações mais rígidas dos órgãos de controle quanto a não realização das atribuições obrigatórias dos nutricionistas no Programa.

Enquanto que em Javaé o responsável técnico abdicou do cargo antes da visita pela equipe do CECANE/UFT e a baixa remuneração ofertada pelo município dificultava o preenchimento da vaga. Entretanto, havia mais de 3 ações de educação alimentar e nutricional previstas no Projeto de Plano Pedagógico de duas das quatro escolas visitadas e relato de execução de ações, contudo sem material comprobatório. Além disso, constatou-se falhas quanto à inserção dos produtos da agricultura familiar nos cardápios e ausência de acompanhamento da aceitação dos mesmos por meio dos testes de aceitabilidade aplicado aos discentes.

Ressalva-se que a ausência de evidências das ações dificulta a possível replicação ou reformulação para melhor alcance dos objetivos, destacando-se as atividades de educação alimentar e nutricional como ferramentas imprescindíveis para a promoção de hábitos alimentares saudáveis e, portanto, promoção da saúde, com sujeitos conscientes do processo saúde-doença (ASSAO, 2012), Segurança Alimentar e Nutricional e Direito Humano à Alimentação Adequada (BRASIL, 2012).

Enfatiza-se que alimentação e nutrição deve integrar as características humanas, como os fatores ambientais, econômicos, biológicos, psicossociais e culturais, em que a elaboração de cardápios com alimentos regionais possibilita a valorização do hábito alimentar daquela comunidade, além de garantir a segurança alimentar e nutricional, diante do consumo de alimentos de maior qualidade nutricional e menor custo (ASSAO, 2012; MARTINS, 2012; BURLANDY, 2017).

Aliada à elaboração de cardápio é imprescindível a avaliação da aceitação dos mesmos, por meio de testes de aceitabilidade, como forma de constatar a qualidade do serviço prestado e evitar a compra de alimentos rejeitados, reduzindo o desperdício (BRASIL, 2017). Dessa maneira, observa-se a necessidade de contratação do responsável técnico em carga horária suficiente, para possibilitar a correta execução das atividades designadas na Resolução n465/2010, como as descritas anteriormente e diagnóstico nutricional dos discentes; capacitação e acompanhamento dos recursos humanos das Unidades de Alimentação e Nutrição; bem como articulação entre agricultores e órgãos competentes para o fomento da agricultura familiar (CFN, 2010).

Em 2016, foi possível a visita em 33 escolas, e no ano de 2017 em 88 instituições. Nos dois anos foi possível identificar as mesmas irregularidades no serviço de alimentação escolar 
como ausência de dedetização e limpeza de caixas d'água, falta de exames médicos e uniformes para manipuladores, falhas nas estruturas físicas, como inexistência de telas milimétricas, gás dentro da cozinha e defeito na ventilação das Unidades de Alimentação e Nutrição.

Ainda, detectou-se a carência de equipamentos essenciais para a produção, como geladeiras, freezers, fornos, balanças e copos graduados. Em 2017 identificou-se a falta de Manuais de Boas Práticas e Procedimentos Operacionais Padrões como uma das principais inadequações. Em visita aos estoques centrais percebeu-se outras incongruências quanto à infraestrutura e organização, que interferem nas condições higiênicas de armazenamento e produção dos alimentos.

As situações incompatíveis com a Resolução 275/2002 (BRASIL, 2002) descritas interferem na produção de alimentação saudável e adequada, diante de falhas em todos os processos de produção dos alimentos, como armazenamento, manipulação e cocção. O responsável técnico deve ser reconhecido como recurso fundamental para a capacitação dos recursos humanos no PNAE e para a adequação da produção de alimentos, em condições higiênico sanitárias satisfatórias (CFN, 2010).

Além do nutricionista, cabe aos gestores a administração dos recursos, viabilização de infraestrutura apropriada e recursos humanos capazes de oportunizar a oferta de alimentação adequada e saudável. Sublinha-se também a realização das atividades previstas em legislação do CAE de acompanhar e fiscalizar a aplicação de recursos e a qualidade higiênico-sanitária dos alimentos ofertados, com trabalho integrado com todos os atores sociais para possibilitar a devida execução do PNAE (BRASIL, 2015; MELLO, 2012).

Nas reuniões com agricultores familiares e discussões sobre a aquisição dos seus produtos, todos os municípios apresentavam os mesmos problemas, como dificuldade pelos agricultores em adquirir o Selo de Inspeção Municipal, Selo de Inspeção Federal e a declaração de aptidão. Além disso, muitos desconheciam o programa e/ou apresentavam receio de ofertar produtos, devido atrasos nos pagamentos ou pelo período de estiagem impedir a entrega de gêneros alimentícios dentro do prazo.

Observa-se que nos municípios em que alcança os 30\% de aquisição da agricultura familiar, como no município Javaé, ocorre ação em conjunto dos órgãos responsáveis pelo contato com agricultores e prefeitura, garantindo orientação aos agricultores, auxílio nos processos burocráticos e planejamento de cardápios adequados à produção local.

Observa-se que outros municípios no país sobressaem-se ao estimular a agricultura familiar no PNAE com ação intersetorial entre Secretarias de Educação, Agricultura e órgãos de apoio técnico aos produtores, de forma a providenciar infraestrutura necessária aos pequenos 
agricultores, facilitando o processo de certificação sanitária, participação na Chamada Pública, plantio e distribuição às Entidades Executoras, bem como geração de renda, promoção de cidadania das comunidades rurais e busca da sustentabilidade (BELIK, 2009; OURIQUES, 2014).

Evidencia-se que produtores rurais apresentam dificuldades na certificação dos produtos, não por falta de qualidade dos mesmos, e sim, em atender as formalidades necessárias para a aquisição das certificações do Selo de Inspeção Municipal e do Selo de Inspeção Federal. Assim, o PNAE torna-se ineficiente em atender as especificações desse grupo, sendo essencial criação de políticas ou legislações que amparem a adequação sanitária dos produtos (BELIK, 2009; OURIQUES, 2014).

Em 2016, identificou-se que 83,3\% dos municípios não compravam da agricultura familiar, sendo que 41,7\% desses nunca realizaram chamada pública e 8,3\% executou, porém não houve a inscrição de agricultores; Enquanto que em 2017, 44\% dos municípios não realizavam a compra. Entre os municípios que realizavam, 21,4\% não apresentaram irregularidades no processo de chamada pública ou prestação de contas referente à agricultura familiar, enquanto que apenas um município, Javaé, alcançava compra maior que 30\% dos recursos federais com produtos de agricultores familiares sem incorreções.

Destaca-se que a justificativa para aquisição menor de 30\% da agricultura familiar pelos municípios, em desacordo com a Legislações vigentes (BRASIL, 2015) foi o alto custo dos produtos, inviabilidade de fornecimento regular, condições higiênico-sanitárias inadequadas, falha na articulação com órgãos competentes e no processo de elaboração de projetos de venda.

A importância da inserção de produtos da agricultura familiar no PNAE é a necessidade de haver políticas públicas para apoio àqueles cuja produção garante a subsistência e fonte de renda, além de promover a ampliação dos estoques de alimentos para a distribuição pelos programas alimentares e garantir o acesso aos alimentos em quantidade, qualidade e regularidade necessária à comunidade, propiciando a inclusão social no campo (BURLANDY, 2017).

Nas reuniões com o CAE nos dois anos de ações, observou-se baixa participação dos membros, devido à falta de tempo e desconhecimento das atribuições do programa; a maioria dos conselhos eram criados para evitar o corte de recursos, não possuindo planos de ação, regimentos internos e/ou atas de atividades realizadas, como é previsto em legislação (BRASIL, 2015).

Observa-se que para a realização das incumbências do CAE, mencionadas anteriormente, é necessário uma atuação responsável e comprometida com a execução do PNAE, tornando imprescindível a capacitação dos conselheiros, propiciando a participação social desses e de outros atores, como pais de alunos, professores, discentes, governantes e imprensa (BELIK, 2009). 
Nas reuniões finais com os municípios houve a participação de grande quantitativo de representantes, totalizando 229 em 2016 e 249 no ano consecutivo. Nessas reuniões apresentavam-se os planos de ações correspondentes para cada entidade executora, com prazos, quais os responsáveis e as justificativas para a execução das ações.

No ano de 2016 houve a participação de 23 municípios nas formações, totalizando a presença de 224 pessoas, enquanto que em 2017 houve a participação de 52 convidados, totalizando a presença de 632 indivíduos. No Gráfico 2 apresenta-se o quantitativo dos diferentes atores sociais que foram às formações nos dois anos.

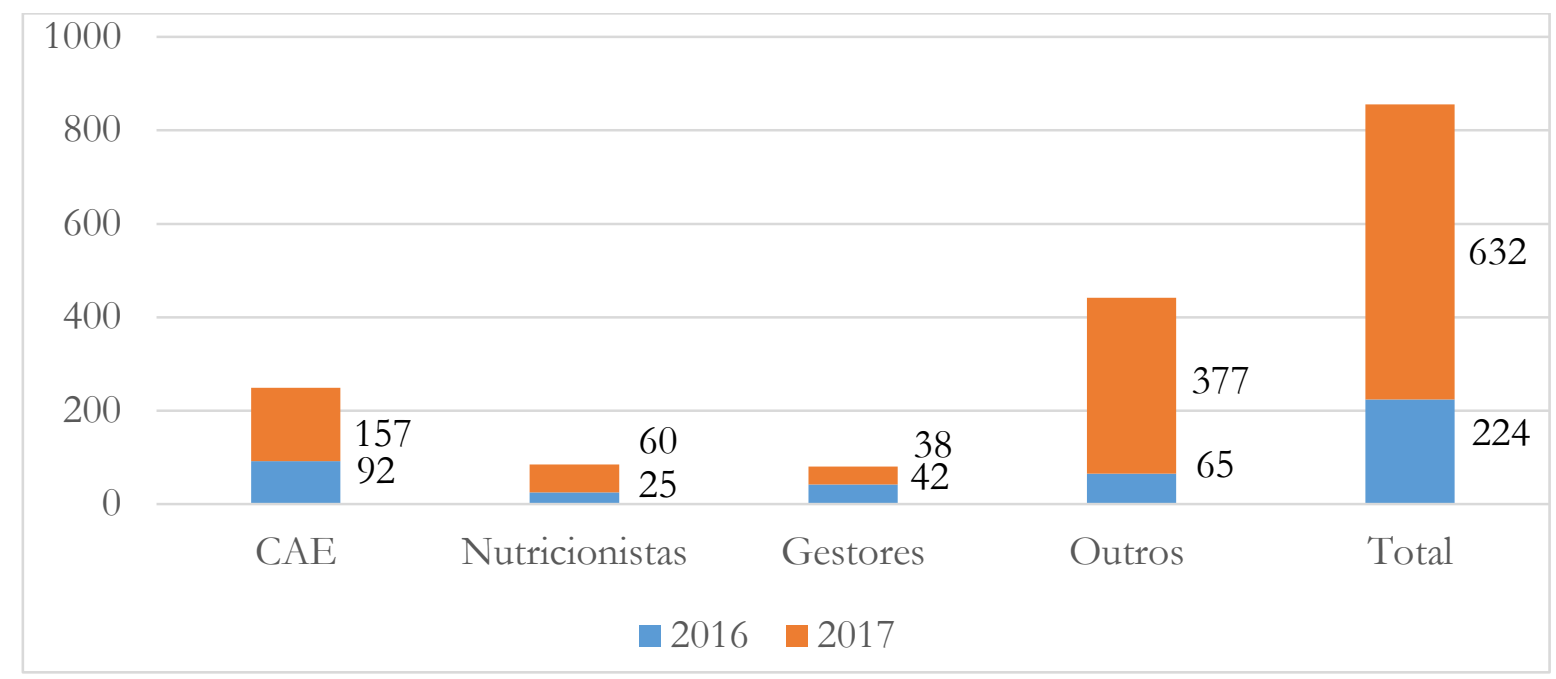

Gráfico 2. Atores sociais participantes nas formações nos municípios assessorados em 2016 e 2017.

Nota: CAE - Conselho de Alimentação Escolar. Fonte: Dados obtidos pelo CECANE/UFT.

Tocantins. 2016 e 2017.

As formações nos dois anos apresentaram boas avaliações dos participantes, com o maior quantitativo de satisfação e anseio por mais eventos, além de que municípios apresentaram relatos positivos relacionados às assessorias e monitoramentos. Apenas 2 participantes no ano de 2017 afirmaram ter dúvidas após a formação, diante das numerosas informações discutidas para o aproveitamento do espaço-tempo das formações.

Frisa-se que as capacitações de todos os atores sociais do PNAE é uma demanda a ser atendida continuamente em todo o Tocantins e Brasil, com a necessidade de capacitações que promovam espaço para diálogo entre os atores, de modo a permitir a troca de experiências e reconhecimento dos obstáculos e soluções para efetivação das legislações vigentes, promovendo participação social e alcance dos objetivos sociais do PNAE (SCARPARO, 2010; SCARPARO, 2013; SILVA, 2013). 


\section{CONSIDERAÇÕES FINAIS}

As ações de assessorias e monitoramentos nos municípios tocantinenses possibilitaram a formação de todos os atores sociais envolvidos com o PNAE (gestores, conselheiros, manipuladores de alimentos, nutricionistas, agricultores familiares e profissionais da educação). Além de esclarecer acerca dos processos burocráticos e legislações atualizadas, possibilitou-se a criação de planos de ações pertinentes aos envolvidos com o programa, com os problemas pontuados, prazos para a resolução dessas demandas, os responsáveis pelas ações e justificativa para a realização, pautada nas legislações.

Dentre as principais dificuldades dos municípios para a execução do PNAE, identificouse a ausência de recursos humanos qualificados para o trabalho no Programa, como nutricionistas; além de falha na articulação com agricultores familiares, com resistência na participação no PNAE, devido possíveis atrasos nos pagamentos, obstáculos em fornecimento regular dos gêneros alimentícios e na aquisição de certificações sanitárias exigidas.

Constatou-se dificuldades de municípios em atender todas os requisitos das legislações, como a contratação de recursos humanos em carga horária suficiente, prover infraestrutura propícia para a produção de alimentos e dispor de infraestrutura para certificação de produtores, como abatedouros legalizados.

Assim, conclui-se que ações intersetoriais entre órgãos competentes, intermunicipais e novas políticas são imprescindíveis para o incentivo à aquisição de produtos da agricultura familiar, com promoção de renda e cidadania às famílias produtoras, do mesmo modo que promove a segurança alimentar e nutricional à população.

Enfatiza-se a necessidade da continuidade das ações dos CECANE devido às alterações de gestores e outros atores, bem como a extensão territorial do Estado, de modo que haja avaliação do cumprimento dos planos de ações nos municípios assessorados, assegurando a efetiva execução do PNAE.

\section{REFERÊNCIAS}

ASSAO, T. Y. Alimentação escolar: percepções dos atores sociais das escolas de um município da região metropolitana de São Paulo [Tese]. São Paulo: Universidade de São Paulo; 2012. 113p.

BELIK, W; CHAIM, N. A. O Programa Nacional de Alimentação Escolar e a gestão municipal: eficiência administrativa, controle social e desenvolvimento local. Rev. Nutrição. Campinas, v. 5, n. 22, p. 595-607, set/out. 2009. 
BRAIL. Fundo Nacional de Desenvolvimento da Educação. Ministério da Educação. Programa Nacional de Alimentação Escolar. Caderno de Legislações 2015. Atualizado em 13 de julho de 2015.

BRASIL. Fundo Nacional de Desenvolvimento Escolar. Alimentação escolar é tema de encontro em Brasília. Acessado em 18 de junho de 2018. Disponível: http://www.fnde.gov.br/acesso-a-informacao/institucional/area-de-

imprensa/noticias/item/11930-alimenta\%C3\%A7\%C3\%A3o-escolar-\%C3\%A9-tema-deencontro-em-bras $\%$ C3\%ADlia: alimentação escolar.

BRASIL. Fundo Nacional de Desenvolvimento Escolar. Dados Financeiros PNAE. Acessado em: 10 de junho de 2018. Disponível: http://www.fnde.gov.br/programas/pnae/pnaeconsultas/pnae-dados-fisicos-e-financeiros-do-pnae : dados financeiros.

BRASIL. Fundo Nacional de Desenvolvimento Escolar. História. Acessado em: 08 de agosto de 2018. Disponível: http://www.fnde.gov.br/acesso-a-informacao/institucional : história.

BRASIL. Lei n⿳1083, de 18 de dezembro de 1950. Dispõe sobre a inspeção industrial e sanitária dos produtos de origem animal. Diário Oficial [da República Federativa do Brasil], Brasília, 19 de dez. 1950.

BRASIL. Ministério da Educação. Manual para aplicação dos testes de aceitabilidade no Programa Nacional de Alimentação Escolar. Brasília, DF: $2^{\circ}$ Ed. 2017. 48p.

BRASIL. Ministério da Saúde. Ministério da Educação. Portaria Interministerial $\mathbf{n}^{\mathbf{0}} \mathbf{1 . 0 1 0}$ de 8 de maio de 2006. Diário Oficial [da] República Federativa do Brasil, Brasília, 9 de mai. 2006.

BRASIL. Ministério do Desenvolvimento Social e Combate à Fome. Marco de Referência de Educação Alimentar e Nutricional para as Políticas Públicas. Brasília - DF, 2012, 68p.

BURLANDY, L. CARVALHOSA, C. S. Conexões entre agricultura familiar e o Programa Nacional de Alimentação Escolar no Brasil: Reflexões sobre o artigo de Schwartman et al. Cadernos de Saúde Pública. Rio de Janeiro, v. 12, n. 22, p. 1-3, 2017.

CONSELHO FEDERAL DE NUTRICIONISTAS - CFN. Resolução CFN n 465/2010. Dispõe sobre as atribuições do nutricionista, estabelece parâmetros numéricos mínimos de referência no âmbito do Programa de Alimentação Escolar e dá outras providências. Brasília, 2010.

HAMERSCHMIDT, I.; OLIVEIRA, S. Alimentação saudável e sustentabilidade ambiental nas escolas do Paraná. Curitiba: Instituto EMATER, 2014.

MARTINS, M. C.; VERAS, J. E. G. L. F.; et al. Segurança Alimentar e o uso de alimentos regionais: validação de um álbum seriado. Rev. Esc. Enferm. USP. São Paulo, v. 6, n. 46, p.1354-1361, 2012.

MELLO, A. L.; VIDAL JÚNIOR, P. O.; et al. Perfil do nutricionista do Programa Nacional de Alimentação Escolar na região nordeste do Brasil. Rev. de Nutrição. Campinas, v. 1, n. 25, p. 119-132, jan/fev. 2012. 
OLIVEIRA, K. C. Um estudo sobre gerenciamento de recurso do PNAE numa escola municipal da cidade de Monteiro - PB no ano de 2016 [monografia]. João Pessoa: Universidade Estadual da Paraíba; 2018. 26p.

OURIQUES, L. A. X. Avaliação das dificuldades de inserção dos alimentos provindos da agricultura familiar na alimentação escolar, nos municípios dos Territórios de Cidadania e Rurais do Rio Grande do Sul [monografia]. Porto alegre: Universidade Federal do Rio Grande do Sul; 2014. 44p.

REZER, D.S. Alimentação escolar: Recursos humanos e equipamentos em escolas públicas de Porto Alegre/RS [monografia]. Porto Alegre: Universidade Federal do Rio Grande do Sul; 2015. 38p.

SANTOS, L. M. P.; SANTOS, S. M. C.; et al. Avaliação de Políticas Públicas de segurança alimentar e combate à fome no período de 1995-2002 - Programa Nacional de Alimentação Escolar. Caderno Saúde Pública. Rio de Janeiro, v. 11, n. 23, p. 2681-2693, nov. 2007.

SCARPARO, A. L. S.; MOULIN, C. C.; et al. Ações do Centro Colaborador em Alimentação e Nutrição do Escolar da Universidade Federal do Rio Grande do Sul. Rev. HCPA. Porto Alegre, v. 3, n. 30, p. 302 -303, 2010.

SCARPARO, A. L. S.; OLIVEIRA, V. R.; et al. Formação para nutricionistas que atuam no Programa Nacional de Alimentação Escolar: uma avaliação da efetividade. Rev. Ciência e Saúde Coletiva, v. 4, n. 18, p.1001- 1008, 2013.

SILVA, D. B. P.; BACCARIN, J. G.; et al. Os agentes sociais e o Programa Nacional de Alimentação Escolar (PNAE): a percepção dos agricultores. In: ENCONTRO INTERNACIONAL PARTICIPAÇÃO, DEMOCRACIA E POLÍTICAS PÚBLICAS: Aproximando agendas e agentes, 2013, Araraquara, 2013. p.1-18.

SOUZA, A. A; BEZERrA, O. M. P. A; BONOMO, E; SILVA, C. A. M. Atuação de nutricionistas responsáveis técnicos pela alimentação escolar de municípios de Minas Gerais e Espírito Santos. Rev. Ciência \& Saúde Coletiva. Rio de Janeiro, v. 22, n. 2, p. 583- 606, 2017.

SPINELLI, M. A. S.; CANESQUI, A. M. O programa de alimentação escolar no estado de Mato Grosso: da centralização à descentralização. Revista de Nutrição, Campinas, v. 1, n. 15, p.105-117, jan/abr. 2002.

VOOS, A. C. Atuação do nutricionista no Programa Nacional de Alimentação escolar (PNAE) no estado RS [tese]. Porto Alegre: Universidade Federal do Rio Grande do Sul; 2009. 48p.

Recebido em: 15/08/2018

Aceito em: 02/04/2019 